\title{
Dampak EI Nino Terhadap Pola Distribusi Ikan Karang dan Pelagis di Wilayah Samudra Pasifik
}

\section{The Impact of El Nino on the Distribution Patterns of Coral and Pelagic Fish in the Pacific Ocean Region}

\section{Janib Achmad dan Satria Krida Nugraha}

Fakultas Perikanan dan Kelautan Universitas Khairun, Ternate

E-mail: mjachmad18@gmail.com/ satria.kridha.n@gmail.com

\begin{abstract}
ABSTRAK
El Nino adalah salah satu fenomena yang berdampak pada perubahan suhu laut. Di wilayah Pasifik Timur Tropis (TEP), El Nino ditandai oleh suhu permukaan laut yang tinggi di wilayah tersebut. Ini memiliki dampak yang berbeda pada organisme laut di wilayah TEP, terutama pada ikan karang dan pelagis. Pelagis yang ditelitiselama El Nino 1972/73, 1982/83 dan 1997/98 memiliki kecenderungan untuk bermigrasi ke daerah yang lebih dingin. Beberapa jenis pelagis memiliki tingkat reproduksi yang berbeda selama El Nino. Sementara ikan karang, yang diketahui memiliki area tetap, memiliki respons berbeda selama terjadiEl Nino. Karena mereka tidak dapat bermigrasi, ikan karang perlu beradaptasi pada perubahan suhu selama El Nino. Akibatnya, selama El Nino jumlahpopulasiikan karang menurun, ini disebabkan oleh faktor reproduksi yang rendah dan jumlah makanan yang terbatas.
\end{abstract}

Kata Kunci :El Nino, Ikankarang,Pelagis, Tropical Eastern Pasific

\section{ABSTRACT}

El Ninoisone of the phenomena that has an impact on sea temperature changes. In the Tropical Eastern Pacific (TEP) region,El Nino is characterized by high sea surface temperatures in the region. This has a different impact on marine organisms in the TEP region, especially in reeffish and pelagic. Pelagic recorded during El Nino 1972/73, 1982/83 and 1997/98 had a tendency to migrate to cooler regions. Some types of pelagic have different reproductive rates during El Nino. While reef fish, which are known to have a fixed area, have different responses during the El Nino. Because they are unable to migrate, reef fish need to adapt on temperature changes during El Nino. As a result, during El Nino the number of reef fishes decreased in population, this was due to low reproductive factors and a limited amount of food.

Keywords : El Nino, Pelagic, Reef Fish, Tropical Eastern Pasific 


\section{PENDAHULUAN}

Suhu merupakan faktor lingkungan terpenting dalam mempengaruhi organisme laut(Somero 1969). Hal tersebut karena suhu dapat mempengaruhi fungsi dari molekul sel, kematian, tingkat pertumbuhan dan reproduksi individu (organisme), distribusi dan ukuran populasi (Moore 1975), serta struktur komunitas serta ekosistem (Glynn 1988; Somero 1969; Brey 1995). Pada tropical eastern Pacific (TEP), El Nino dan pemanasan global diakui sebagai penyebab peningkatan suhu permukaan laut (Barber dan Chavez 1983). Selama El Nino, suhu permukaan air laut pada TEP telah meningkat (dari hari sampai bulan) mencapai $30-32^{0} \mathrm{C}\left(4-5^{0} \mathrm{Cdi}\right.$ atas batas normal) (Mora dan Ospina, 2001). Disisi lain, sebagai konsekuensi pemanasan global, peningkatan $0.5-1^{0} \mathrm{C}$ per dekade pada suhu laut di TEP telah banyak dilaporkan (JokielandColes 1990). Pengetahuan mengenai upper temperaturetolerance limits atau batas toleransi suhu dari organisme laut pada TEP menjadi penting, ketika pemanasan laut dihubungkan dengan pemanasan global dan El Nino, dan memiliki dampak negatif terhadap perubahan beberapa populasi di laut seperti mamalia, burung, ikan dan invertebrata.

Kenaikan suhu atau tingginya suhu akan memengaruhi ikan karang atau reef fishes karena ikan tersebut memiliki juvenile dan adult benthic phase, sehingga mereka tidak dapat menghindar dari perubahan suhu dengan berpindah dari satu wilayah ke wilayah lain, seperti yang dilakukan spesies pelagis (Mora dan Ospina, 2001). Pada kenyataannya, beberapa populasi ikan karang telah menurun, dan bahkan di beberapa wilayah tertentu telah menghilang selama kejadian El Nino. Namun, penyebabnya masih belum diketahui. Perubahan populasi ikan karang berhubungan dengan El Nino masih belum banyak dilaporkan. Hal ini mungkin disebabkan karena terbatasnya data.

Menurut Niquen dan Bouchon (2004), Dampak fenomena El Ninojuga menghasilkan perubahan substansial dalam sumberdaya pelagis,meskipun ketika terjadi perubahan suhu yang ekstrim ikan pelagis mampu berpindah ke tempat yang lain, ini tetap akan merubah proses biologis dan perilaku pelagis bahkan penurunan populasinya. Ukuran dan reproduksi dari beberapa jenis pelagis mengalami perubahan ketika terjadinya El Nino Hal ini berpengaruh pada jumlah populasi ikan pelagis (Valdivia, 1976).

Tujuan dari tulisan ini adalah melihat pengaruh fenomena El Nino terhadap sumberdaya ikan karang dan ikan pelagis. Ikan pelagis dan ikan karang yang di bahas dalam makalah ini memiliki kesamaan wilayah, yaitu di wilayah tropis. Hal ini akan menarik karena ikan pelagis dan ikan karang memiliki pola hidup yang berbeda, dimana ikan pelagis memiliki pola hidup berpindah dari suatu wilayah ke wilayah lain, sedangkan ikan karang hanya menetap pada satu wilayah.

\subsection{Kondisi Perairan TEP Saat El Nino}

Karakteristik pada peristiwa El Nino ditandai dengan perubahan suhu antara Paita dan Chimbote $\left(5^{0} \mathrm{~S}-10^{\circ} \mathrm{S}\right)$ di Pasifik, yang disebabkan oleh intrusi kenaikan suhu permukaan pada khatulistiwa yang menghasilkan anomali suhu permukaan laut yang ektrim hingga $8^{0} \mathrm{C}$ di atas rata-rata dalam fase puncak. Namun, antara Calao dan Ilo $\left(12^{0}-17^{0} \mathrm{~S}\right)$, variasinya lebih kecil dan anomali mencapai suhu permukaan lautnya mencapai +6 hingga $+2^{0} \mathrm{C}$ (Zuta et al., 1984; (Bjernes, 1966).

El Nino memiliki perbedaan bentuk Data menunjukkan pada tahun 1971, 1982 dan 1996, terdapat periode musim dingin sebelum terjadi El Nino,periode anomali suhu yang cukup tinggi pada tahun 1972 terlihat cukup lama, sedangkantahun 1982-1983, jauh lebih singkat. Sebaliknya, kenaikan suhu tahun 1997-1998, memiliki durasi panjang dan kuat dalam intensitasnya (Zutaetal., 1976). Dalam ketiga kasus tersebut, terlihat dua puncak perkembangan, dimana yang kedua memiliki intensitas yang lebih tinggi (Gambar 1). 

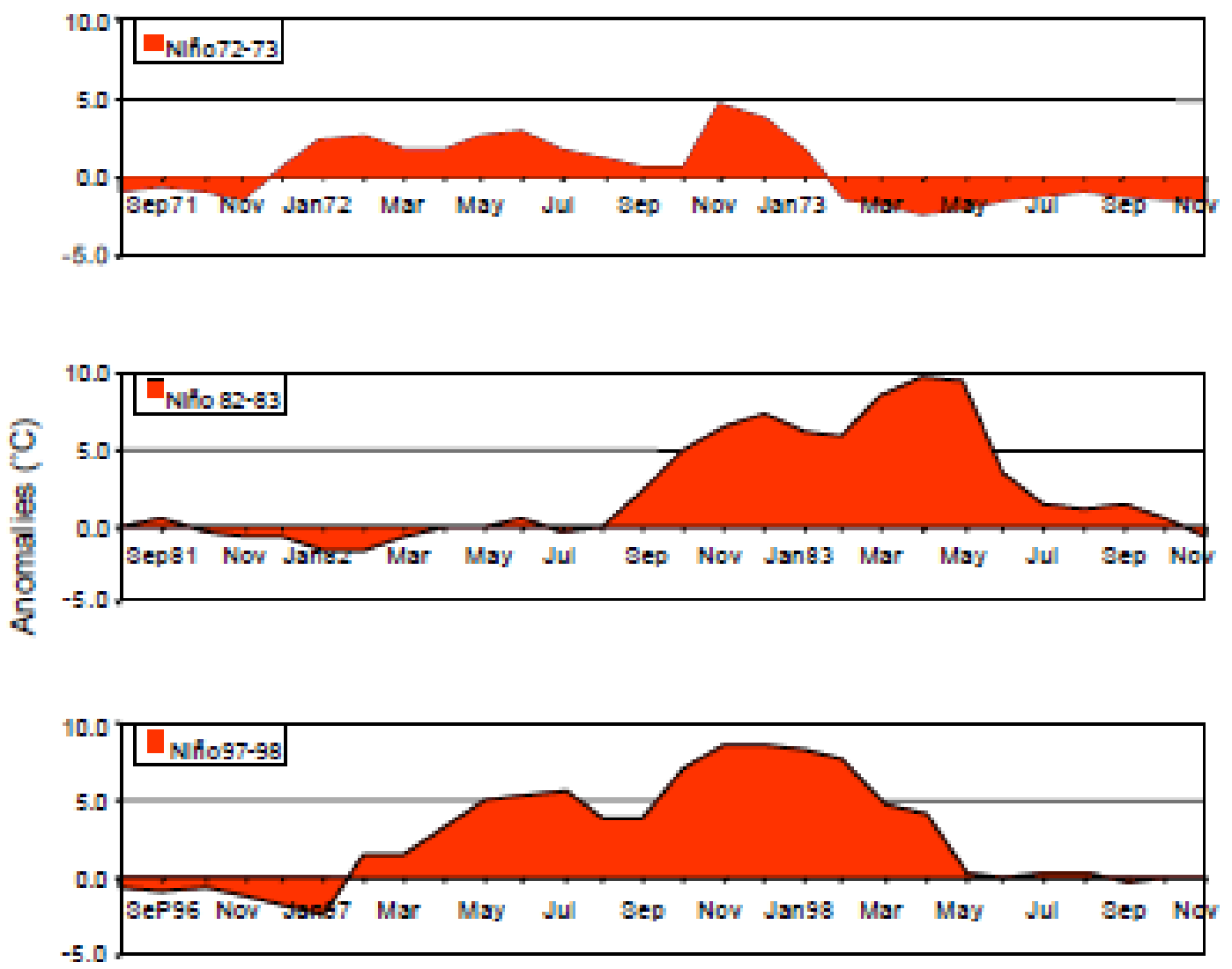

Gambar 1 : Anomali suhu permukaan laut yang diamati di Chicama $\left(07^{\circ} 42^{\prime} \mathrm{S}-7^{\circ} 26^{\circ} \mathrm{W}\right)$ sebelum, selama dan setelah El Nino (Mora dan Ospina, 2001).

\subsection{Pengaruh Perubahan Suhu Permukaan Laut Pada Ikan Karang}

Suhu dapat mengurangi keragaman populasi dengan memengaruhi ketahanan hidup dari benthic individualatau dengan memengaruhi reproduksi dan rekruitmen (pengaruh pada migrasi atau imigrasi lebih sedikit disebabkan karena sifat menetap dari ikan karang) (Mora dan Ospina, 2001).El Nino merupakan fenomena yang berhubungan dengan pemanasan suhu di TEP. Intensitasnya bervariasi. Namun, El Nino 1982-1983 dan 1997-1998 merupakan fenomena yang paling kuat (Quinn et al. 1987; NOAA 2001). Selama kondisi tersebut, suhu permukaan laut mencapai $32^{\circ} \mathrm{C}$ dalam berbagai garis lintang di TEP. Berdasarkan hasil penelitian Mora dan Ospina (2001), semua spesies ikan karang yang diteliti masih toleran terhadap suhu selama terjadinya fenomena El Nino (Gambar 1). Sehingga, kematian karena tingginya suhu permukaan laut akibat El Nino bukan merupakan alasan untuk penurunan populasi ikan karang selama fenomena tersebut.

Menurut TercandColes 1990; Roemmich 1992 danStrongetal., 2000, dalam beberapa tahun terakhir, telah dilaporkan bahwa suhu laut di TEP meningkat hingga $1^{0} \mathrm{C}$ per dekade.Tercatat bahwa spesies yang paling tidak toleran memiliki toleransi suhu $8^{0} \mathrm{C}$ di atas rata-rata suhu permukaan laut di TEP(Mora andOspina,2001. Hal ini menunjukkan bahwa ikan karang hidup jauh dari upper thermal-tolerance limits dan oleh karenanya, dalam kondisi singkat atau short time,pemanasan global dapat membahayakan spesies tersebut. Jika suhu laut terus meningkat, dalam waktu satu abad dari sekarang, suhu laut dapat melebihi toleransi suhu dari beberapa ikan karang dan terancam punah. Resiko tersebut, dapat terjadi lebih cepat jika suhu selama El Nino juga meningkat dengan adanya trend pemanasan global. 
Menurut Mora and Ospina (2001), bahwa kemampuan ikan karang untuk beradaptasi pada kenaikan suhu laut harus dibedakan antara short-term temperature increases (STI) selama fenomena seperti El Nino dan long-term temperature increases (LTI) berhubungan dengan fenomena seperti pemanasan global laut. Selama STI, ikan membutuhkan adaptasi cepat karena perubahan suhu, sedangkan pada LTI, adaptasi dapat lebih lambat. Tingkat adaptasi baik STI dan LTI bergantung pada keragaman genetik dan life-history characteristics, seperti generation time. Pada STI, beberapa ikan karang berada dalam kondisi yang sangat membahayakan sampai terancam punah, tidak hanya karena rendahnya keragaman intraspesifik pada toleransi suhu, tetapi juga disebabkan karena generation time pada ikan karang lebih lambat dari waktu suhu laut mengalami kenaikan. Walaupun dalam kondisi LTI ikan karang terancam punah, meraka masih memiliki kesempatan untuk beradaptasi karena banyaknya keturunan akan meningkatkan keragaman genetik.



Gambar 2 : Criticalthermalmaxima pada 15 jenis ikan karang di Pulau Gorgona dan perbadingannya terhadap suhu permukaan rata-rata di beberapa lokasi pada wilayah TEP selama terjadinya El Nino (Mora dan Ospina, 2001).

\subsection{Dampak El Nino Pada Populasi Ikan Karang}

Dampak El Nino yang berpengaruh padakenaikan suhu, akan berpengaruh pada penurunan populasi ikan karangkarena kenaikan suhu juga berhubungan dengan penurunan produksi primer plankton (Barber dan Chavez 1983; Arntz dan Fahrbach 1996; Mora dan Ospina, 2001). Kemungkinan, selama El Nino, ikan berada dalam kondisi starvation atau kelaparan. Kelaparan tersebut dapat memengaruhi jumlah populasi dengan peningkatan mortalitas atau secara tidak langsung menurunkan toleransi suhu (Hutchison, 1976) atau upaya reproduksi (Hirshfield, 1980). Efek kelaparan selama El Nino tersebut, dapat berbeda 
antar tiap spesies ikan karang. Tidak seperti planktivores untuk herbivora, ketersediaan makanan selama El Nino meningkat, karena peningkatan alga yang berlebihan akibat dari kematian karang yang masif.

Menurut Hutchison(1976), larva ikan lebih sensitif pada kenaikan suhu daripada saat dewasa, hal ini mengimplikasikan bahwa, selama El Nino, larva merupakan subjek yang rentan terhadap peningkatan suhu, starvationdan interaksi antara starvationdengan toleransi suhu. Oleh karena itu, El Nino dapat memengaruhi ketahanan hidup larva,terbatasnya larva pada plankton dan rendahnya rekruitmen ikan karang selama El Nino tidak hanya akan meningkatkan kematian larva, tetapi dapat juga menyebabkan rendahnya reproduksi ikan kerang, akibat dari rendahnya reproduksi ikan selama El Nino(Wellington and Victor, 1985). Kondisi El Nino akan memengaruhi reproduksi melalui mekanisme fisiologis (contohnya memengaruhi peningkatanhormonal atau menurunkan ketersediaan energi untuk reproduksi karena efek dari starvation pada beberapa spesies ikan karang). Sebagai tambahan, ikan karang dapat merubah strategi reproduksi mereka dengan menurunkan reproduksi selama El Nino. Hal ini akan mencegah kehilangan energi dalam produksi gamete ketika kondisi tidak menguntungkan terjadi. Perubahan pada strategi reproduksi selama El Nino ini telah diteliti pada beberapa jenis bivalves dari Peru. Intinya, El Nino mungkin memengaruhi reproduksi dan keberlangsungan hidup benthic dan pelagic individuals bergantung pada kehidupan dan strategi reproduksi dari ikan karang. Namun, penjelasan mengenai efek El Nino pada ikan karang dapat lebih memungkinkan apabila dilakukan penelitian lebih lanjut dan long-term monitoring (Urban andTarazoba, 1996)

\subsection{Perubahan Distribusi Ikan Pelagis Saat Terjadi EI Nino}

Data migrasipada Gambar 3, menunjukkan adanya perpindahan, dari utara ke selatan dan barat ke timur, dari beberapa spesies laut. Beberapa di antaranya berasal dari perairan Panaman, yang diamati di wilayah pantai utara-tengah Peru selama fenomena El Nino 19971998. Hal tersebut berkaitan dengan ikan seperti tuna, ikan bilis atau billfishes, ikan makarelpasifik dan ikan makareljackyangmuncul di perairan Peru, diikuti oleh longnoseanchovy, ikan parang untai (Opisthonemalibertate), ikan cakalang (Katsuwonuspelamis), dan mitophidae (Diogenichthyslarernatus)(Chirinosdevildoso, 1976; Kameya, etal., 2001; Niquenetal., 1999; Bouchone t al., 2001).

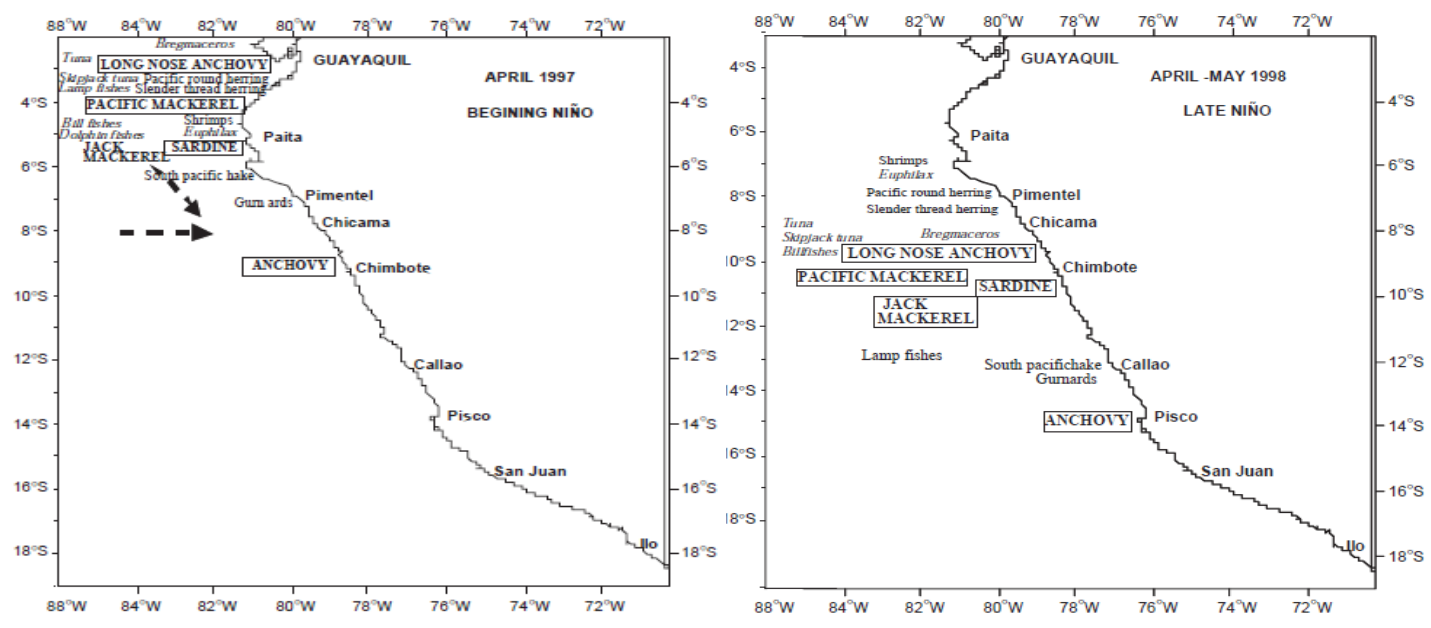

Gambar 3: Migrasi spesies pelagis selama El Nino 1997 - 1998 di Pantai Peru.(Niquen and Bouchon 2004) 
Kondisi hangat atau warm condition di bagian utara pantai peru pada puncak terjadinya El Nino, menentukan pergerakan ikan teri, menuju pantai dan sebagian besar berada pada 30 $\mathrm{km}$ dari pantai. Perpindahan ini menghasilkan konsentrasi jumlah ikan yang tinggi yang membuat spesies tersebut sangat rentan untuk ditangkap. Secara cepat, ikan teri ini mulai bergerak ke selatan Chimbote dan ikan teri yang terdeteksi pada wilayah utara-tengah pantai Peru, hanya terletak antara kedalaman 20 sampai $80 \mathrm{~m}$ ketika El Nino terjadi. Perubahan tersebut menyebabkan perubahan strategi dalam memancing, dengan hasil tangkapan terbesar terjadi pada malam hari ketika ikan bergerak lebih dekat ke permukaan(Niquen andBouchon (2004).

Sedangkanikan sarden, konsentrasi terbesar bergerak dari Paita, menuju Pimentel dan Chicama secara bersamaan mendekati pantai. Dalam kasus tertentu dimana mereka mencapai Ilo di selatan dengan konsentrasi lebih tinggi dari Chimbote, dekat dengan pantai seperti terlihat pada El Nino 1997-1998 (Gambar 4). Pola yang serupa juga ditemukan pada fenomena El Nino 1972-1973 (Zuzunaga, 1985).
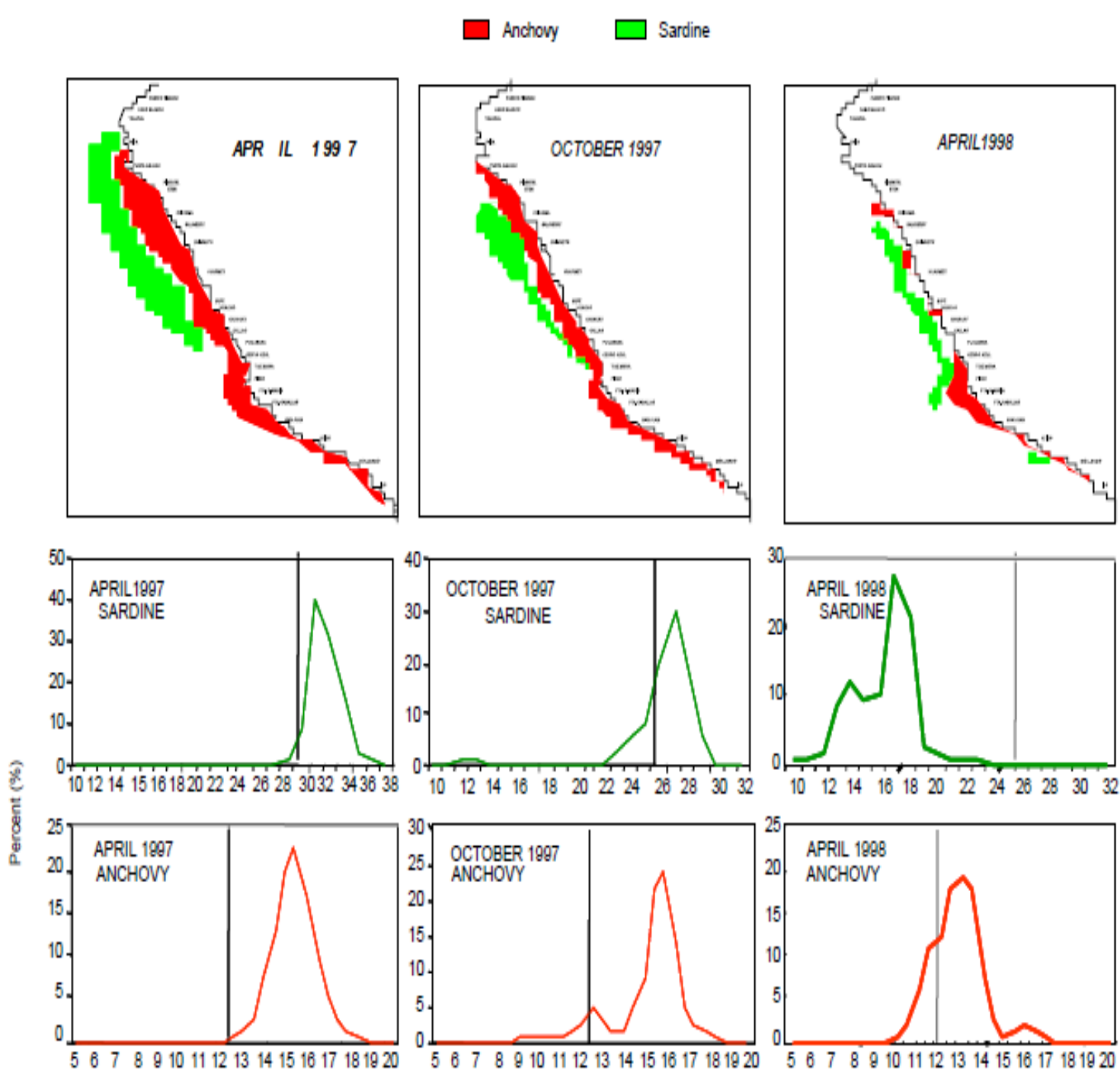

Gambar 4 : Perubahan distribusi dan ukuran teri dan sardine selama April 1997 - Juni 1998(Niquen and Bouchon 2004) 


\subsection{Perubahan Proses Reproduksi}

Pada Gambar 6, selama El Nino 1997-1998, siklus reproduksi ikan teri terganggu dan intensitas bertelur menjadi berkurang,sebaliknya, pada ikan makarelpasifik dan sarden intensitas bertelur meningkat pada awal El Nino dan selama El Nino, proses bertelur sarden dan makarel pasifik terdeteksi selama akhir fenomena El Nino. Kematangan seksusal lebih dominan dengan panjang 26-27 cm, tetapi saat kondisi tersebut, jumlah sarden dewasa secara seksual dengan panjang 18-20 cm terlihat signifikan, yang menunjukkan bahwa kondisi El Nino disukai pada spesies ini untuk bereproduksi(Perea etal,. 1998).

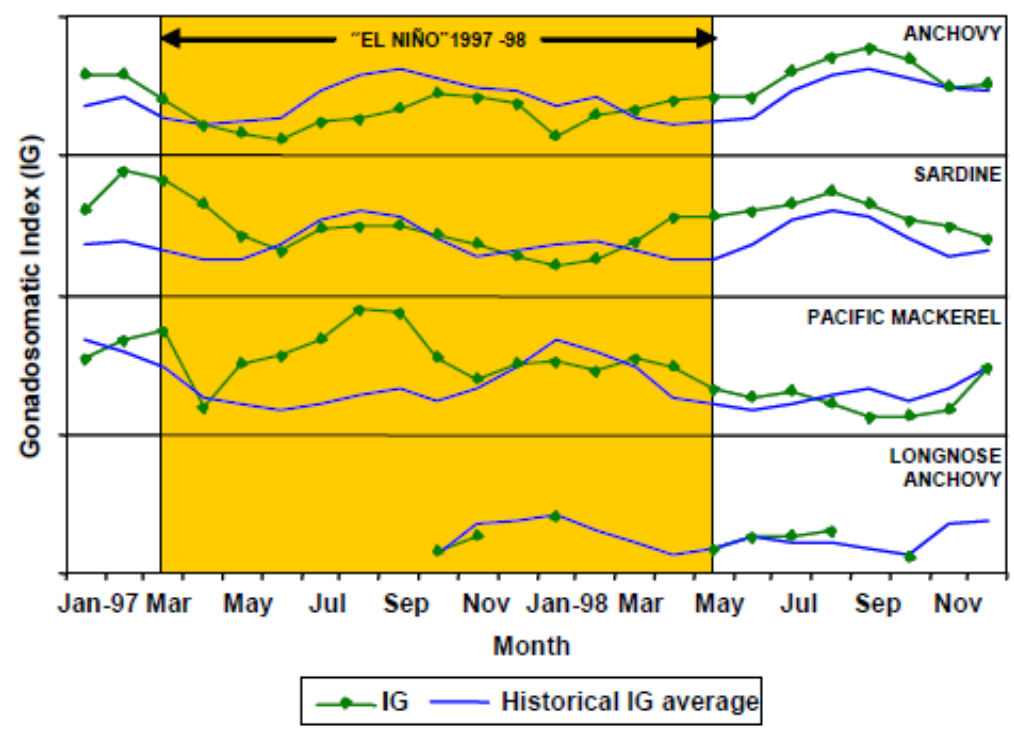

Gambar 5 : Index Gonadosomatix (IG) jumlah pelagis selama El nino 1997 - 1998 (Niquen andBouchon2004)

Kondisi lingkungan seperti ini mungkin lebih cocok untuk ikan sarden, sehingga memungkinkan sarden remaja untuk bereproduksi. Hal ini dapat dilihat pada kisaran ukuran sarden saat kondisi tersebut di California, sebanyak 50\% matang seksual dengan panjang 19 $\mathrm{cm}$. menyebutkan bahwa sarden California dan sarden Peru-Chile mungkin berasal dari tempat yang sama dan berasal dari satu spesies. Kejadian early spawning inimengidentifikasikan bahwa sarden pada pantai Peru selama tahun El Nino memiliki perilaku serupa seperti sarden California pada tahun normal. Hal ini tidak diketahui apakah peristiwa tersebut bersifat sementara atau permanen di tahun berikutnya (Macewicz dan Parrishetal., 1996).

\section{Kesimpulan}

El Nino dapat menyebabkan populasi ikan karang akan mengalami penurunan. Hal ini disebabkan karena dua hal, yang pertama karena ikan berada dalam kondisi kelaparan karena sumber makanan berkurang pada saat El Nino, sedangkan yang kedua adalah karena larva ikan sangat sensitif pada kenaikan suhu.

Ikan pelagis selama terjadinya El Nino mengalami migrasi ke tempat perairan yang lebih dingin, sebagaimana yeng teramati di pantai Peru, ikan pelagis berpindah dari utara ke selatan dan dari barat ke timur. Selama terjadinya El Nino, tingkat reproduksi ikan pelagis berbeda pada masing-masing spesies. Pada ikan teri, siklus reproduksinya terganggu dan 
intensitas bertelur menjadi berkurang. Sebaliknya, pada ikan makarel pasifik dan sarden, intensitas bertelur meningkat pada awal El Nino dan selama El Nino

\section{Daftar Pustaka}

Barber RT, Chavez FP, 1983. Ocean variability in relation to living resources during 1982-83 El-Nino. Science 319:279-289.

Bjernes J., 1966. Survey of El Nino 1957-58 in its relation Tropical to Pacific meteorology. Bulletinof I ATCC 12 (2), 1-42.

Brey T, 1995. Temperature and reproductivemetabolism in macrobenthic populations. Mar Ecol Prog Ser 125:87-93.

Coles S L, Jokiel PL, Lewis CR, 1976. Thermal tolerance in tropical versus subtropical Pacific coral reefs. Pac Sci 30:159-166.

Chirinos de Vildoso. A., 1976. Aspectosbiologicos del Fenomeno El Nino 1972-73. Parte I: Distribucionde la Fauna. In: Proceedings of the Workshop El Nino. Guayaquil, Ecuador, 4-12 December 1974. FAO Fishing Information 185. 63-79.

Glynn PW, 1988. El Nino-Southern Oscillation 1982-1983: near shore population, comunity, and ecosystem response. Annu Rev Ecol Syst 19:309-345.

Hirshfield M, 1980. An experimental analysis of reproductive effort and cost in japanese medaka, Orizias latipes. Ecology 61:282:-292.

Hutchison V, 1976. Factors influencing thermal tolerance of individual organism. In: Esch GW, Mcfarlane R (eds) Symposium Series of the National Technical Information Service, Spring-field, Va,m pp 10-26.

Macewicz, J. 1996. Pacific Sardine adult reproductive parameters.CALCOFI Report 37,140151.

Mora C., Ospina, A., 2001. Tolerance to high temperatures and potential impact of sea warming on reef fishes of Gorgona Island (Tropical Eastern Pacific). Marine Biology 139: 765-769.

Niquen M, M Bouchon, 2004. Impact of El Nino Events on pelagic fisheries in Peruvian waters. Deep sea Res 51:563-574.

Parrish, R.H., Saws, R., Grant, S., 1989. The monotypic sardine, Sardine and Sardinops: their taxonomy, distributionstock structure and zoogeography. J. Fish. Aquat. Sci.46, 2019-2036.

Perea, L.A., Buitron, B., Mecklenburg, E., 1998. Reproductive state, partial fecundity and frequency of it spawns from the Peruvian anchoveta to autumn beginnings 1998. Inf. Inst.Mar Peru 135, 147-152.

Somero GN, 1969. Enzymatic mechanism of temperature compensation; immediate and evolutionary effects of temperature on enzym aquatic poikilotherms. Am Nat 103:517.

Urban J, tarazona J. 1996.Effect of Elnino/Southern Oscillation on the population dynamics of a Garisolida population (Bivalvia: Psammobiidae) from Bahia Independencia, Peru. Marbiol 125:725-734.

Valdivia J, 1976. Aspectos biologicos del Fenomeno El Nino 1972-73. Parte I: La poblacio' $\mathrm{n}$ de anchoveta. In: Proceedings of the Workshop El Nino, Guayaquil, Ecuador, 412 December 1974. FAO Fishing Inf. 185, 80-93.

Wellington GM. Victor BC. 1985.El Nino mass coral mortality: a test of resource limitation in a coral reef damselfish population .Oecologia 68:15-19. 
Zuta S., Farfán M., Morón O. 1984. Caracterı'sticas principales del mar frente al Peru'durante la evolucio'ndel evento El Niño 1982-83. Rev. Com. Perm. Paci'fico Sur 15, 141-178.

Zuzunaga, J. 1985. Changes in the equilibrium between the anchovy and the sardine populations in the upwelling System off Peru Bulletin Inst. Mar Peru (ExtraordinaryVolume)El Nino its impact in the marine fauna 107-117. 